\title{
Esrârını Molino'dan aldım / Çaldım velî mîrî malı çaldım: Antonio Mascis'in İtalyanca-Türkçe Sözlüğü Üzerine (1677)'1
}

\section{Ömer YAĞMUR²}

APA: Yağmur, Ö. (2018). Esrârını Molino'dan aldım / Çaldım velî mîrî malı çaldım: Antonio Mascis'in İtalyanca-Türkçe Sözlüğü Üzerine (1677). RumeliDE Dil ve Edebiyat Araşttrmaları Dergisi, (12), 68-

83. DOI: $10.29000 /$ rumelide. 472752

\section{$\ddot{0} \mathbf{z}$}

Türkçe transkripsiyon metinleri Batı Türkçesinin Osmanlı sahası içerisinde, Arap alfabesinin gölgelediği bazı fonetik ve morfolojik değişim ve gelişmeleri görmemizi sağlayan önemli verilerdir. Genellikle Batılı Türkologlar tarafından yapılmış çalışmalarla bu metinler dil alanında uzmanlaşmış araştırıcıların istifadesine sunulmuştur. Benim çalışmam 17. yüzyll transkripsiyon metni olan, 12 yl İstanbul'da bulunmuş İtalyan çevirmen Antonio Mascis'in 1677 yllında Floransa'da bastırdığı Vocabolario Toscano, e Turchesco adlı sözlüğü üzerine olacaktır. Toskana Grandükü Cosimo iii'e (d.1642-ö.1723) ithaf edilen sözlük XXXIV+38+290 sayfadan oluşur. Grandük'e övgü ile başlayan ilk bölümün ardından ikinci bölümde Türkçenin dilbilgisi kuralları ele alınır. Mascis'in grameri Vladimir Drimba'ya göre 1641'de Roma'da baslan Giovanni Molino'nun Dittionario della lingua Italiana, e Turchesca'sının içinde yer alan Türkçe gramerinin üzerinde değişiklik yapılmış bir imitasyonundan ibarettir. Drimba, aynı zamanda sözlüğün de imitasyon olduğunu belirtir. O dönemde intihalin yaygın olduğunu ve hatta telif hakkı kavramının olmadığını düşünürsek bu gayet normal karşlanmalıdır. Fakat Mascis'in sözlüğü gerek Türkçe kelimelerin telaffuzu gerekse yeni Türkçe kelimeler ilavesi ve İtalyanca madde başları yönüyle Molino'dan bir hayli farklılıklar gösterir. Mascis'in sözlüğü özgün bir eser olmasa dahi Molino'nun kötü bir taklidi değil, 1641'den 1677'ye İstanbul ağzındaki bazı değişmeleri gösteren gözden geçirilmiş yeni bir baskı olarak düşünülebilir. Bugünün yaklaşımıyla, Mascis'in en büyük hatası eserinde hiçbir şekilde Molino'dan bahsetmemiş olmasıdır. Araştırmam bahsedilen bu farklılıkları ortaya koymayı amaçlamaktadır.

Anahtar kelimeler: Antonio Mascis, Giovanni Molino, transkripsiyon metinleri, Osmanl Türkçesi, İtalyanca.

\section{Esrârını Molino'dan aldım / Çaldım velî mîrî malı çaldım: On the Italian- Turkish Dictionary of Antonio Mascis (1677)}

\begin{abstract}
Turkish transcription texts are essential data that enables us to see some phonetic and morphological changes and developments within the Ottoman field of Western Turkish, overshadowed by the Arabic alphabet. These texts, which are generally made by Western Turkologists, are presented to the use of researchers who are specialized in the Ottoman language field. My work will be on the 17th-century transcription text Vocabolario Toscano, e Tvrchesco, which was printed in Florence in 1677 by the Italian translator Antonio Mascis, who had been in Istanbul for 12 years. The dictionary dedicated to
\end{abstract}

Bu makale, Otto-Friedrich-Universität Bamberg ev sahipliğinde 19-21 Eylül 2018 tarihlerinde düzenlenen Turkologentag 2018, Third European Convention on Turkic, Ottoman and Turkish Studies'de sunulan bildirinin genişletilmiș hâlidir. Dr. Öğr. Üyesi, Bolu Abant-İzzet Baysal Üniversitesi, Fen-Edebiyat Fakültesi, Türk Dili ve Edebiyatı Bölümü, omeryagmur@gmail.com, ORCID ID: oooo-0001-8286-0925; [Makale kayıt tarihi: 11.10.2018-kabul tarihi: 20.10.2018] 


\begin{abstract}
the Grand Duke of Tuscany Cosimo iii (1642-1723) consists of XXXIV $+38+290$ pages. After a chapter of praising the Grand Duke, in the second part, the grammatical rules of Turkish are discussed. According to Vladimir Drimba, Mascis's grammar consists of a modified imitation of the Turkish grammar of Giovanni Molino, which was published in 1641 in Rome, in the Dittionario della lingua Italiana e Turchesca. Drimba also states that the dictionary is also an imitation. This situation should be considered reasonable if we consider that plagiarism is widespread at the time, and even the concept of copyright does not exist. However, Mascis' dictionary is quite different from Molino concerning both the pronunciation of Turkish words and the addition of new Turkish words and the Italian entries. Mascis's glossary is not an imitation of Molino, even if it is not an original work, but it can be considered as a revised new edition, which shows some changes in Istanbul dialect from 1641 to 1677 . With today's approach, Mascis' biggest mistake is that he never mentioned Molino in his work. My research aims to reveal these differences.
\end{abstract}

Key words: Antonio Mascis, Giovanni Molino, transkriptionstexte, Ottoman Turkish, Italian.

\title{
o. Giriş ve Notlar
}

2015-2016 yllarında Ca' Foscari Üniversitesinin davetiyle post doktora araştırmamı Venedik'te, İtalyanlar tarafından hazırlanmış Türkçe transkripsiyon metinleri üzerinde yapmıştım. Asistanlığım sırasında, ilk olarak Karakartal (2004: 89-95) ve sonrasında Kurtböke'nin (1994: 540) yazılarından haberdar olduğum bir Türkçe transkripsiyon metnini burada inceleme firsatı buldum. ${ }^{3} \mathrm{Bu}$ kitap, Venedik Biblioteca Nazionale Marciana'da antika basma eserler (Testo a stampa 'antico') bölümü ANT 17616 envanter ve C 022C 161 yer numarasıyla kayıtlı İtalyancanın Toscana ağzı - Türkçe şeklinde hazırlanmış bir sözlüktür. Eserin tam ismi şöyledir:

\footnotetext{
"Vocabolario Toscano, e Tvrchesco - Arricchito di molte Voci Arabe, Persiane, Tartare, e Greche, Necessarie alla perfetta cognizione della stessa lingua Turchesca - Con la giunta di alcuni Rudimenti Grammaticali vtili per impossessarsi del vero Idioma Turchesco."

[Türklerin dili hakkında mükemmel bilgiye sahip olmak için pek çok Arapça, Farsça, Tatarca ve Yunanca madde ile zenginleştirilmiş - Türk dilinin doğru şekilde öğrenilmesi için bazı faydalı gramer kuralları ilavesiyle - Toscana dili ve Türkçe Sözlük].
}

Kitap 1677 yılında Niccolò Nauesi adlı yayımcı tarafından o dönemde Toskana Grandukalığının merkezi olan Floransa'da (Firenze) basılmıştır. Toskana Grandükü Cosimo iii'e (d.1642-ö.1723) ithaf edilen sözlük XXXIV+290+38 sayfadır. Bir takdim ve ardından sözlük ile ilgili üç sayfalık Avvertimento [= uyarı]'dan oluşan birinci bölümden (I-XXXIV) sonra ikinci bölüm (1- 290 s.) Toscana dili - Türkçe sözlükten oluşur. Aynı cildin içinde olmasına rağmen sözlükten bağımsız sayfa numaraları verilmiş üçüncü bölüm (1-38 s.) ise, 'Rvdimenti Grammaticali per ben tradurre l'idioma Toscano in Turchesco' [Toscana dilini en iyi şekilde Türkçeye tercüme etmek için gramer kuralları] başlığı verilmiş gramer bilgisi kısmıdır.

Kitabın girişindeki COMPOSTO DA ANTONIO MASCIS Napoletano Interpetre [= interprete] del SERENISSIMO COSIMO III GRAN DVCA DI TOSCANA ifadesinden yazarın Toscana Grandükü Cosimo iii de' Medici'nin tercümanlarından biri olan Napolili Antonio Mascis (Mascis de Naples interprète) olduğu anlaşılıyor.4 Mascis'in doğum-ölüm tarihleri ve yaşamı ile ilgili bilgi bulunmuyor,

3 Bu metin üzerinde 17. yüzyl Türkçesini inceleyen bir kitap çalışmam TÜBİTAK projesi dâhilinde devam etmektedir. Yazarın bu ifadesine rağmen http://www.medici.org web sitesinde 'The Medici Archive Project' altında taranıp dijital ortama aktarılmıs Medici ailesi arsivinde Antonio Mascis ismini bulamadım. 

(p. 68-83)

fakat sözlüğünün bir maddesindeki ifadesi onun Napoli Krallığının hangi şehrinden olduğunu açıkça gösteriyor:

Rodi, città famosa del Regno di Napoli, Paese dell'Autore = Rodos scehri (Masc. 167-8).

[Rodi, Napoli Krallığının ünlü şehri, yazarın memleketi].

Burası dönemin Napoli Krallığının içerisinde, Adriyatik Denizine kıyısı bulunan Rodi Garganico şehridir. Mascis'in Rodi'ye Türkçe karşıllk olarak verdiği Rodos şehri ile (günümüzde) Yunanistan Rodos (Póסo $)$ farklı şehirlerdir. Her iki şehrin İtalyanca isim benzerliğinden dolayı yazar ikisini de Türkçeye Rodos olarak çevirmiş olmalıdır. Yunanistan Rodos için bkz.:

Rodi città, isola in leuante $=$ Rodos ada ve scehri (Masc. 168) Isola di Rodi = Rodos adassi (Masc. 75).

Mascis, kitabının takdiminde İstanbul'da Saray'a yakın olarak 12 yll geçirdiğini belirtiyor. Dostu Niccolò del Ricco'nun onun için yazdığı bir şiirde Mascis'in İstanbul'a genç yaşta geldiği

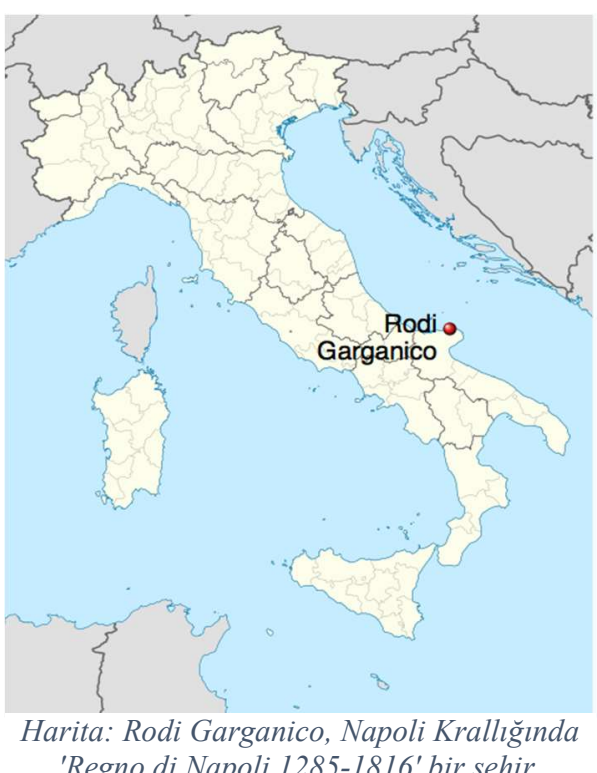
'Regno di Napoli 1285-1816' bir șehir. anlaşıllyor (şiirin tam metni bu bölümün sonunda verilmiştir):

...ho auuto tra quelle angustie fortuna di viver dodici anni cõtinoui nel proprio Serraglio in Constantinopoli... (Masc. XXIX).

... che sì nell'eccellenza, e pregio, come nel numero ecce dono quelli del Gran Muftì, che per lo spazio di dodici anni ho continouamente maneggiati... (Masc. XXVI).

Onun angustie fortuna [angùstia 'lack; paucity' Rgzz. 1520] ifadesinden aslında İstanbul'da bulunmaktan pek de hoşnut olmadığı anlaşılıyor. Satırların devamında ise İstanbul'da hangi görevle bulunduğu açıç̧a yazılmıştır:

... servendo di Secretario a Apsaidi Hefenti allora gran Muftì, che capo della Religione Maommettana risuona... (Masc. XXIX).

Mascis, İstanbul'da bulunduğu süre içerisinde Apsaidi Hefendi'nin katipliğini/tercümanlığını yaptığını ifade ediyor. 'gran Muftì' ifadesinin karşılığı 'şeyhülislam' olmalıdır. Çünkü o, che capo della Religione Maommettana risuona yani 'Muhammet dininin sesini yeniden yükselten başkan'dır. Fakat kitabın Floransa'da basıldı $\breve{g} 1677$ tarihinde Osmanlının 43. Şeyhülislamı 21.02.1674 - 26.09.1686 tarihleri arasında görev yapmış Çatalcavî (Çatalcah) Ali Efendi'dir (Altınsu 1972: 94). Kitabın ön sözünün, basımından birkaç yıl önce yazıldığını varsayarak kronolojide biraz geriye gidildiğinde Osmanlı Şeyhülislamları şunlardır (bkz. Altınsu 1972: 269):
40. Bursavî Esirî Muhammed (Mehmed) Efendi
20.03.1659-03.02.1662
41. Sunizâde Esseyyid Mehmed Emin Efendi
03.02.1662 - 21.11.1662
42. Minkarizâde Yahya Efendi
21.11.1662 - 21.02.1674

Bu kronolojiye göre Mascis, 12 yl boyunca Şeyhülislamlık yapmış [Apsaidi = ? Esseyyid Ebu Seyyid ?Ebu Said] Minkarizâde Yahya Efendi'nin tercümanlığını yapmış ve Yahya Efendi'nin 11 yll 3 aylık 
meşîhâtından hastalığı üzerine ayrılmasından (Altınsu 1972: 93) sonra İtalya yarım adasına dönmüş olmalıdır.

Mascis, bulunduğu carica'da [= görev] (Masc. sözlüğündeki karşllğ̆ılla ehl-i kizmet) sarayın dil uzmanları arasında, imparatorlukta yaygın olarak kullanılan dilleri ögrenme imkanı bulur:

...nella qual carica ho auuto larghissimo campo d'impossessarmi delle lingue già dette, che come piú comuni in quel vastissimo Impero s'adoprano, e sotto le scuole de' più fioriti, ed esperti maestri del Serraglio in esse esser ammaestrato... (Masc. XXIX).

Burada vurgulanması gereken nokta Mascis'in Serraglio'da yani Osmanlı Sarayında tercüman olarak bulunduğunu ifade etmesidir. XVI. yüzyıldan itibaren ihdas edilen tercümanlık görevinin en başındaki kişi Babıâli tercümanı ya da Divân-ı Hümayûn tercümanı olarak adlandırılmaktaydı (Hitzel 1995: 17; Pakalın 1971: 466). Daha alt konumlarda Osmanlı Sarayında çeşitli kalemlerde görevlendirilen tercümanlar da bulunmaktaydı. Bu tercümanlar anlaşmaları, konuşmaları ve resmi evrakları çeviren, bazen de diplomatik görevler üstlenen kişilerdi (Hitzel 1995: 17).

Mascis'in İstanbul'da 12 yll bulunması, üstelik Saray'da tercüman olarak görev alı İmparatorlukta kullanılan dilleri öğrendiği iddiası onun sözlüğüne bir derece daha önem atfediyor. Çünkü bu durumda, Türkçeyi İstanbul'da öğrenmiş ya da daha önce öğrendiği bu dili burada ilerletmiş; yani yazı dilinin yanı sıra konuşulan XVII. İstanbul Türkçesine de hâkim olması gerekiyor.

Kitabının ön sözünde, yakın arkadaşı Cristofano Arnoldo'nun kendisine yazığı bir mektuptan o yıllarda Polanyalı bir tercümanın hazırladığı Viyana'da basılan Latince - Türkçe bir sözlüğün varlığından haberdar olduğunu söylüyor. İçerdiği birçok madde başının yanı sıra mükemmel bir baskıya sahip olduğu söylenen bu sözlük 1680 yllında Viyana'da basılan Franciscus à Mesgnien Meninski'nin Thesaurus'undan başka bir şey değildir.

...So che in Vienna da vn Signor Pollacco interpetre di S. M. Cesarea vn altro Vocabolario Turco latino si stampa, come per vna lettera dell'Eruditissimo Sig. Cristofano Arnoldo ad vn letterato mio cordialissimo amico scritta ho veduto, il quale non solo sarà di molte voci abbondante, ma con magnificenza impresso (Masc. XXIX).

Takdim (s. I-XXXIV), Mascis'in sözlüğünün hemen başında dostu Niccolò del Ricco'nun Mascis için yazdığı bir methiye ile bitiriliyor:

Ben'a ragion chi sopra l'Arno impera,

Il tuo ualor, la tua uirtude stima,

E se in tenera età barbaro clima

Prouasti, o godi e nel Gran Duce spera.

Non più fortuna tua Turca, e seuera

Si mostri, ma t'inalzi all'alta cima

Delle glorie maggior' onde t'imprima

Il nome, la uirtù con fama uera:

Porti pur di colà dall'Oriente,

Tesori immensi chi appetisce l'oro, 
Che quello manca, e si riduce a niente.

Di maggior stima sia il tuo tesero,

Ammirato dall'Orto, e dal Ponente,

Ch'accresce all merto tuo maggior decoro (Masc. XXXIV).

Türkçesi:

'Arno bölgesine hükmeden, senin değerini ve erdemini de haklı olarak doğrudan değerlendirebilir. Gerçi çocuk yaşında barbarların iklimini tecrübe ettinse de şimdi eğlen, rahatına bak ve Büyük Düka'da ümidin olsun. Talihin Türk gibi sert olmasın. Aksine, yüceliğin zirvelerine kadar yükselsin ve senin adın şanlı olsun. Zira sen bize Şarktan öyle ebedî bir hazine getiriyorsun ki altına tapanlar altının sonunda bir hiç, senin hazinenin ise sonsuz bir kıymet olduğunu bilsinler. Getirdiğin hazine öyle bir değere layık ki hem Şarkta hem Garpta hayranlık yaratacak. Çünkü o senin öz değerine bir kat daha değer katıyor.' (Karakartal 2004: 90).

Bu övgüden anlaşıldığı kadarılla dostu Niccolò del Ricco Mascis'in sözlüğünden 36 yll önce 1641'de Roma'da basılan Dittionario Italiano, Turchesco'dan haberdar değildir!

\section{Antonio Mascis: Vocabolario Toscano, e Tvrchesco}

Mascis'in eseri İtalyancanın Toscana ağzına göre düzenlenmiş İtalyanca - Türkçe sözlüktür. Her bir sayfa iki sütundan oluşur. Aynı dönemde hazırlanmış Giovanni Molino (1641) ve Franciscus à Mesgnien Meninski (1680) sözlükleri gibi sütunlar değil, sayfalar numaralandırılmıştır. Sözlük içerisinde Türkçe olduğu kadar doğal olarak Osmanlı Türkçesine Arapça, Farsça, Yunanca, İtalyanca, Ermenice, İspanyolca, Sırpça, Macarca gibi dillerden geçmiş kelimelere de yer verilmiştir. Mascis, zaman zaman hatalı da olsa, bazı madde başlarında kelimelerin İtalyanca, Arapça, Farsça, Yunanca ya da Tatarca kökenli olduklarını belirtir:

Örnekler:

occhio $=\quad$ ghios; cescim, persiano; aini, arabo (Masc. 109)

[göz; çeşm, farsça; ayni, arapça]

uigliaccheria, poltroneria = nehbetlich; mariolluch, italiano (Masc. 269)

[nehbetlik (< nekbet nikbet); maryolluk, italyanca]

maryol (ital.) 'edebsız, deysız, yüzsız, 'ārsız, şáḳī...' (Men. Onom. 1199)

scabello, banco piccolo $=\quad$ ischemre, greco (Masc. 181)

[iskemre, yunanca] < yun. skammi.

Bazen kelime kökenlerinde hatalıdır:

angelo $=$

sparagio, erba $=$ melech, arabo; ferisc-te, tartaro (Masc. 13)

[melek, arapça; ferişte, tatarca]

Fakat osm. färištä < fars. firišta (< sogd. frišti) (Räsänen VEWb. 145).

enchinar; tartaro (Masc. 218)

[enkinar; tatarca]

Fakat osm. enǵinar < yun. òyนıvá $\rho \alpha$ (Meyer 29). 
Tartaro 'Tātār' (Ciadyrgy 848)] Masc. Tartaro ile Doğu Türkçesini kastediyor olmalıdır.

Tabii ki burada yeni keşfedilmiş, daha önce hiçbir araştırıcının görmediği bir sözlükten bahsetmiyorum. Mascis'in sözlüğü Stanisław Stachowski, Luciano Rocchi gibi Türkçe transkripsiyon metinleri üzerinde çalışan Türkologlar tarafından da incelenmiştir. Vladimir Drimba 1992'de yayımladığı 'La grammaire turque d'Antonio Mascis (1677)' adlı makalesinde yukarıda da bahsettiğim Mascis'in sözlükle aynı cilt içerisinde bulunan 38 sayfalı Rvdimenti Grammaticali per ben tradurre l'idioma Toscano in Turchesco adlı Türkçe gramerini incelemiştir. Dirimba, Mascis'in sözlük ve gramerinin imitation [= taklit] olduğunu belirtir:

"... le dictionnaire aussi bien que la grammaire d'A. Mascis sont des imitations d'après Dittionario Della Lingua Italiana, Turchesca. Roccolto da Giovanni Molino Interprete." (Drimba 1992: 110).

[...A. Mascis'in hem sözlüğü hem de grameri Tercüman Giovanni Molino'nun hazırladığı Dittionario Della Lingua Italiana, Turchesca'nın bir taklididir].

Fakat dikkat çekici bir şekilde, Mascis kendi kitabıyla aynı zamanda henüz baskısı yapılmakta olan Signor Pollacco interpetre yani Meninski'nin sözlüğünden takdim'de bahsederken şekil ve içerikçe Molino'ya çok benzeyen sözlüğü ve hatta verilen örnekler haricinde Molino'dan farksız grameriyle Molino'dan neden bahsetmiyor?

Kurtböke (1994: 540), Mascis'in çalışmasının içerik ve şekilce Molino'ya çok benzediğini ifade etmesine rağmen o da Karakartal (2004: 89-95) gibi bunun taklit bir çalışma olduğundan bahsetmez. Burada Rocchi'nin, 165o'de hazırlanan Arcangelo Carradori sözlüğünün önemli bir kısmının Molino'dan (1641) alındığını belirttikten sonra, şu tespiti önemlidir:

"...which is hardly surprising if we consider that there was no copyright in those days and that plagiarism was common practice - Mascis (1677), to take one example, is nothing but a reworking of Molino." (Rocchi 2011: 214).

[... o günlerde telif hakkının olmadığını ve intihalin yaygın bir uygulama olduğunu düşünürsek (bu) hiç de şaşırtıcı değildir - bir örnek vermek gerekirse, Mascis (1677) Molino'nun yeniden işlenmesinden başkası değildir].

\section{Giovanni Molino ve Dittionario Italiano, Turchesco}

Molino'nun tam kimliği Elżbieta Święcicka'nın Archivio di Stato di Venezia'da (Venedik Devlet Arşivi) bulduğu belgelerle gün yüzüne çıkmıştır. 10 Ağustos 1626 tarihli belgeye göre gerçek adıyla Yovhannēs Ankiwrac (Hovhannes Ankyouratsi; Ankiwrac'i Yuanni Molino) Ankara'dan Venedik'e çalışmak için gelmiş 34 yaşında bir Ermeni'dir. Eşi bu dönemde İstanbul'dadır. Gençliğinde, Roma Katolik okulu Collegio dei Neofiti'de eğitim gördüğü için İtalyanca ve İtalyan edebiyatını iyi bilmektedir. Aynı zamanda, belgede onun Türkçeyi iyi konuştuğu ve Türkçe konuşma diline de hâkim olduğu vurgulanır (Święcicka 2000).

Bu belgeye göre Molino'nun doğum tarihi 1592 olmalıdır (Siemieniec-Gołaś 2005: 12). Onun ölüm tarihini ise bilmiyoruz. Mascis'in Vocabolario Toscano, e Tvrchesco'yu bastırdığ 1677 tarihinde Molino 85 yaşında olmalıdır ki o dönemin hayat şartlarını göz önüne aldığımda onun bu tarihte hayatta olmadığını düşünüyorum. Belki bu nedenle Mascis, basımı üzerinden ancak 36 yıl geçmiş Molino sözlüğünü yeni bir isimle ona hiçbir şekilde atıfta bulunmadan yeni bir sözlük gibi bastırabilmiştir.

\section{3. İntihal mi revizyon mu?}



(p. 68-83)

Molino (1641) ve Mascis (1677) sözlükleri şekilce birbirinin neredeyse aynı olmasına rağmen karşılaştırdı ğım kadarıyla her iki içerikte dikkat çeken farklılıklar vardır:

\section{1. İtalyanca kelimelerde}

Mascis sözlüğündeki İtalyanca madde başları Molino'dan çoğu zaman fonetik ve bazen de kelime yönüyle farklıdır. Bunun nedeni Mascis'in sözlüğünü Toskana ağzına göre düzenlemiş olmasıdır:

Örnekler:

\begin{tabular}{l|l} 
Molino & Mascis \\
\hline $\begin{array}{l}\text { I. vnguento 'mehlem' (485) } \\
\text { II. } \varnothing\end{array}$ & $\begin{array}{l}\text { I. unguento 'melem, surulegiech [sürülecek]' (273) } \\
\text { II. *mucillaggiane 'melem' (101); }\end{array}$ \\
\hline $\begin{array}{l}\text { I. cappotto 'capot [kapot]' (80) } \\
\text { II. Ø. }\end{array}$ & $\begin{array}{l}\text { I. capotto 'capot' (26) } \\
\text { II. ***altanbarco, vestimento 'cappot' (176) }\end{array}$ \\
\hline mandola, frutto 'badem meiue' (243) & $* * *$ mandorla, frutto 'badem meiue [badem meyve]' (88)
\end{tabular}

*Toskana ağzı 1613: mugellaggine, *mucillaggine 'humor crassus [akışkan, sıvı yağ]' (Politi 523) = Osm. ed. merhem, günl. melhem (merhem, vul[go] melhem) 'impiastro' (Men. 4588) < fars. murham, ar. marham 'Salbe, Hautcreme' (Räsänen VEWb. 335).

** Toskana ağzı 1775: saltanbarco 'capoto; vestimeto da galeotti [suçlu/hükümlü elbisesi]' (Patriarchi 63); Piyemonte ağzı (Milano'nun batısındaki bölge, Piemonte'de konuşulan bir İtalyan ağzı) 1843: saltanbarco 'vestito da contadino [köylü/çoban elbisesi]' (Ponza 11) = Osm. 1665: kapūt 'cappotto' (BdP I 341) < saltan '?soltan sultan' + barco 'parka 'a pelt or jacket made from pelt'; Aleut < Russian < Samoyed' (OnEtym.)

****Toskana ağzı 1613/1775 *mandorle = mandola 'frutta del mondorlo' (Politi 486; Patriarchi 197).

3.2. Yeni kelimeler

Mascis sözlügünde Molino'da bulunmayan bir hayli madde başı eklenmiştir. Bunların Türkçe karşılıkları Molino'da hiç bulunmayan kelimeler olabileceği gibi bu yeni Türkçe karşıllklar Molino sözlüğündeki bazı fiillerin yeni çekimleri ya da bazı kelimelerin genişletilmiş şekilleridir.

3.2.1. Mascis'te bulunup Molino'da bulunmayan Türkçe kelimelere örnekler:

Allah alsun

Krş. osm. 1680: Allāh saḳlasun, Allāh saḳlayü bekleyüvere, Allāh göstermesün (allāh saklasun, allāh saklaiü bekileiüwere, allāh giöstermesün) 'Dio guardi, Dio ce ne guardi' (Men. 395-6).

balijos ieri [baliyos yeri]

*Mol. balyos kelimesi de bulunmuyor.

tolga Iddio (248)

uece di consolo (264). 
behenmech [behenmek]

Osm. 1680: begenmek (begienmeki) 'accettare, hauer grato, gradire, piacere' (Men. 866).

bascden cicarmach [başden çıkarmak]

Krş. osm. 168o: azdürmak, azıtmak, ızlāl etmek, ayartmak (azdürmak, azytmak, yzlāl e., aiartmak) 'disuiare...' (Men. 161).

\begin{tabular}{|c|c|}
\hline bela etmech [bela etmek] & gastigare (55) \\
\hline cianach [çanak] & scodella (189); scudella, scodella (193) \\
\hline diuanè ieri, dinghile ieri [divane yeri, dinle yeri] & *uditorio, luogo d'vdienza ' (263) \\
\hline $\begin{array}{l}\text { Krş. osm. 1650: mehkeme (mehchieme) 'auditorio' } \\
\text { (Car-R. 240). }\end{array}$ & $\begin{array}{l}\text { Toskana ağzı 1863: *uditòrio 'auditorio, udienza' } \\
\text { (Fanfani 1007). }\end{array}$ \\
\hline \multicolumn{2}{|l|}{ giamedangi [camedancı] } \\
\hline $\begin{array}{l}\text { Osm. 1680: cāmedān (ḡiāmedan) = geysi koyacak } \\
\text { (gieisi kojağiak) 'valigia; portamantello' (Men. 1563). }\end{array}$ & ualigiero (261) \\
\hline hapsi olunmisc [hapsi olunmış] & imprigionato (64) \\
\hline iccimech bardaghi [içmek bardagi] & uaso per bere (262) \\
\hline \multicolumn{2}{|l|}{ pilig [pilic] } \\
\hline $\begin{array}{l}\text { *Mol.'da sözlükte değil fakat Indice Turchesca'da var } \\
\text { (indeks): piligz (Burada metin içi sayfa ve satır } \\
\text { numarası verilmemiş). }\end{array}$ & pollastra (131) \\
\hline
\end{tabular}

3.2.2. Mascis, Molino'da aynı İtalyanca madde başındaki kelimelerin Türkçe karşılıklarını değiştirir ya da buraya yeni karşılıklar ekler. Bu eklenen kelimeler çoğunlukla Molino'da bulunmaz.

\begin{tabular}{|c|c|c|c|}
\hline $\begin{array}{l}\text { Ortak İtalyanca } \\
\text { karşllığ }\end{array}$ & Molino & Mascis & Açıklamalar \\
\hline ouero & $\begin{array}{l}\text { ya honuz (276); } \\
\text { honuz (287) }\end{array}$ & ala (116) & $\begin{array}{l}\text { An.-ağl. alā 'belki' (DS 170) } \\
\text { M. honuz < ? fars., osm. 1680: henūz (henūz) } \\
\text { 'ancora, hora, adesso...' (Men. 5506); } \\
\text { hanuz, anuz (< fars. hanūz) 'daha, henüz' (Codex } \\
\text { 710, 422). }\end{array}$ \\
\hline${ }^{1}$ fronte & $\operatorname{agın}$ [ağın] (178) & $\begin{array}{l}\text { alm, } \\
(281)\end{array}$ & $\begin{array}{l}\text { An.-ağl. ann 'karşı; alın' (DS 275) } \\
\text { Osm. aln, alın (aln, alyn) 'fronte' (Men. 401); alın, } \\
\text { any (alyn, ann-) 'fronte' (Pianz-R. 37); alın, vulg. } \\
\text { ann 'the forehead' (Redh. 190); an 'fronte' } \\
\text { (Letellier 116); }\end{array}$ \\
\hline${ }^{2}$ fronte & $a g$ [ağ] (156) & al (53) & $\begin{array}{l}\text { An-ağl. al 'ön, ön taraf' (DS 166) = 'ön, karss' } \\
\text { (TETTL I 135) < etmlj. EsT al 'front, facing, prior } \\
\text { position' (Clauson 121). }\end{array}$ \\
\hline
\end{tabular}

piacere (126)

disuiare (41)

Toskana ağzı 1863: *uditòrio 'auditorio, udienza' .

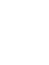




\begin{tabular}{|c|c|c|c|}
\hline disuiato & $\begin{array}{l}\text { zergârdan, avara } \\
\text { (126) }\end{array}$ & $\begin{array}{l}\text { başsden } \\
\text { çıarmış (41) }\end{array}$ & $\begin{array}{l}\text { Osm. 1680: sergerdān (sergiardān) 'attonito, } \\
\text { marauigliato, stupito, stupido, confuso, stordito; } \\
\text { errante, vagabondo; abbassato, auuilito' (Men. } \\
\text { 2597). Osm. 1680: a avāre (āwāre) 'otioso, } \\
\text { sfacendato, poltrone, errante, vagabondo, } \\
\text { scioperato, stordito' (Men. 478). }\end{array}$ \\
\hline imbiancamento & $\begin{array}{l}\text { debesir-ile } \\
\text { agartmış (191) }\end{array}$ & $\begin{array}{l}\text { debeşirile } \\
\text { agartmak; } \\
\text { beyazlatmak } \\
(62)\end{array}$ & $\begin{array}{l}\text { Imbiancare 'badanalamak, kireçlemek' fiilin } \\
\text { isimleşmiş formu. Masc.'in Türkçe karşllı̆̆ daha } \\
\text { doğrudur. }\end{array}$ \\
\hline $\begin{array}{l}\text { albore (Masc. } 10) \\
/ / \text { colonna; trave }\end{array}$ & $\begin{array}{l}\text { direk (95); katul } \\
(465)\end{array}$ & $\begin{array}{l}\text { direk }(10,30, \\
254)\end{array}$ & $\begin{array}{l}\text { An-ağl. hatıl 'kereste; duvar örülürken araya } \\
\text { konulan kalın yuvarlak ağaç' (DS 2306); } \\
\text { İtal. àlbore 'lo stesso che arbore' [ağaç kelimesiyle } \\
\text { aynı] (Borrelli 65). }\end{array}$ \\
\hline trauicello & katzlcuk (466) & direkcik (254) & \\
\hline
\end{tabular}

3.2.3. Mascis sözlüğüne Molino'da bulunmayan birçok yer adı eklemiştir. Yer adları konusunda Mascis sözlüğü Molino'ya göre zengindir. Mascis yer adları konusuda Venuti (1576) ve farklı tarihlerde birçok kez baskısı yapılmış Galesini (1662) sözlüklerinden faydalanmıştır.

Örnekler:

Masc. Poggio Reale, luogo vicino à Napoli 'Sultan Teppè' (131) = Mol. Ø

Masc. Sagonto, città di Spagna ' Saguntu scehri, Ispaniade' (174) $\neq$ Mol. Ø

Masc. Sabioncello, terra o castello di Schiauonia 'Sabin casaba, Curuattè' (172) $\neq$ Mol. $\varnothing$

Masc. Candia, città; Xilo Castro, città della Morea 'Castro scehri' $(26,278) \neq$ Mol. Ø

Masc. Sabioniera, porto di Candia 'Castronin ilemoni [Kastro'nın limanı]' (172) $\neq$ Mol. Ø

\section{3. İki sözlük arasında dikkat çekici bazı fonetik farklılıklar:}

3.3.1. Batı grubu (Bartın, Amasra, Çaycuma, İzmit-Taşköprü ve kısmen Ova ağızları; seyrek olarak y > y değişmesi Giresun-Tirebolu, Ordu-Ünye, Perşembe) ve Doğu grubu (Urfa merkez, Ceylanpınar, Tuzluca Azeri) ağızlarında görülen / $\mathrm{y} /$ sesinin akıcılaşma hadisesi Anadolu ağızlarındaki Kıpçak Türkçesi etkisini göstermektedir (Karahan 1996: 21-22). /y/ ünsüzü Rumeli ve bu ağızın uzantısı olan İstanbul ağızında ise /n/ ile karşılanır (Karahan 1996: 20).

Osm. ed. 1680: dejız (Men. 2106) kelimesinin telaffuzu Molino'da sistemli olarak degiz ve daha ileri safhasıyla deyiz şeklindedir. Fakat Mascis kelimenin telaffuzunu Rumeli ă̆ızlarındaki $\mathrm{y}>\mathrm{n}$ gelişmeli şekliyle çoğunlukla denez olarak gösterir.

Örnekler

Molino Mascis Ortak İtalyanca anlamlar 


\begin{tabular}{|c|c|c|}
\hline $\mathrm{y}>\mathrm{g}(\breve{\mathrm{g}})$ & $y>n$ & \\
\hline Gelibolı degizi (246) & Gelbol denezi (90) & mare di San Giorgio \\
\hline Girit degizi (245) & Girit denezi (89) & mare di Candia \\
\hline degiz bogazı (357) & denez bogazı (163) & ristretto di mare \\
\hline $\mathrm{y}>\mathrm{g}(\breve{\mathrm{g}})>\mathrm{y}$ & $y>n$ & \\
\hline Akdeyiz adalarl (223) & Akdenez adaleri (76) & isole dell'Arcipelago \\
\hline deyizi geçmek (464) & denez geçmek (253) & trapassare il mare \\
\hline $\mathrm{y} / / \mathrm{y}>\mathrm{g}(\breve{\mathrm{g}})$ & $y>n$ & \\
\hline $\begin{array}{l}\text { deyiz yalust (421) // degiz yalust } \\
\text { (247) // degiz yalss (234) }\end{array}$ & $\begin{array}{l}\text { denez yaluss (90) // denez yahss } \\
\text { (82)// denez yal (223) }\end{array}$ & $\begin{array}{l}\text { spiaggia di mare } / / \text { maremme (cioè } \\
\text { vicino alla marina) // lido, lito del } \\
\text { mare }\end{array}$ \\
\hline $\mathrm{y} / / \mathrm{g}>\mathrm{g}(\breve{\mathrm{g}})$ & $\mathrm{y}>\mathrm{n} / / \mathrm{y}>\mathrm{g}(\breve{\mathrm{g}})$ & \\
\hline $\begin{array}{l}\text { deyiz furtunasl (154) // degiz } \\
\text { f(i)rtunast (449) }\end{array}$ & $\begin{array}{l}\text { denez furtunasl (242) // degiz } \\
\text { furtunasl (52) }\end{array}$ & $\begin{array}{l}\text { fortuna di mare // tempesta di } \\
\text { mare }\end{array}$ \\
\hline
\end{tabular}

Dikkat edilirse / $\mathrm{y}$ / sesinin bir ileri safhası olan ve Anadolu ağızlarında görülen $\mathrm{y}>\mathrm{y}$ gelişmesi Mascis'te yoktur. Buna karşllık $\mathrm{y}>\mathrm{g}(\breve{\mathrm{g}})$ gelişmesi Mascis'te birkaç kelimede daha görülür:

\begin{tabular}{l|l|l} 
Mol. & $\begin{array}{l}\text { bagaile [bağa ile < baya ile] (32) } \\
\text { Krş. osm. 1789: benim-ile } \\
\text { (benímile) 'meco' (Pianz-R. 51). }\end{array}$ & con meco \\
\hline \multirow{2}{*}{ bir gün sōgra (190) } & $\begin{array}{l}\text { iki şekilli: } \\
\text { I. bir gün sogra (62) } \\
\text { II. bir gün sōgra (273) }\end{array}$ & $\begin{array}{l}\text { il giorno dapoi (di poi) // un dì } \\
\text { dopo }\end{array}$
\end{tabular}

Mascis'te $\mathrm{y}$ > g değişmesini gösteren kelimeler Molino'dan alınmış olmalıdır.

3.3.2. Kelime başında $h>\varnothing$ değişmesi Türkiye Türkçesi ağızlarında da görülmekle birlikte, bu özellik Doğu ve Batı Rumeli ağızlarında karakteristik ve yaygındır (Gülsevin 2017: 67). Molino ve Mascis sözüklerinde bu karakteristik farklılık çok belirgindir:

Örnekler:

\begin{tabular}{l|l|l} 
Molino & Mascis & Meninski \\
\hline hamur (194, 248), kamur (233) & amur (81, 91) & hámīr, günl. hámūr (1945-6) \\
\hline hereket etmek (264, 265) & $\begin{array}{l}\text { areket etmek (101), ariket etmek } \\
(102)\end{array}$ & háreket etmek (1747). \\
\hline hat-ı şerif (413) & att-ı şerif (215) & hátt-ı şerīf (1910)
\end{tabular}


Esrârını Molino'dan aldım / Çaldım velî mîrî malı çaldım: On the Italian-Turkish Dictionary of Antonio Mascis (1677) / Ö. Yağmur (p. 68-83)

\begin{tabular}{l|l|l} 
Habeş vilayeti (5) & *Abeş vilayet (3) & Hábeş (1721) \\
\hline **hala (492) & ala (279) & hăle, günl. hala (1843)
\end{tabular}

*Abeş, Abeşistan (Pianz-R. 117).

**babanın kız kardeşi.

Buna mukabil Mascis'te geçen az sayıdaki kelimede /h/ türemesi görülür:

\begin{tabular}{l|l|l} 
Molino & Mascis & Meninski \\
\hline${ }^{*}$ bu ane $(36,258)$ & bu hanede (11) & $* * \bar{a} n(432)$ \\
\hline hases (375) & ****asas (48), hasas (180) & $* * *$ áses (3263)
\end{tabular}

*krş. bu an/anda.

**ane 'augenblick, moment' $\leq$ ar. ànā, çkl. anan 'zeit, zeitraum' (StAr. I 19).

*** ar. 'asas 'devriye' (TETTL I 207).

****Fakat Molino'da /h/ türemeli şekliyle kaydedilmiş kelime Mascis'te baştaki ünsüzü düşürülerek verilir. Aslî şekli de budur zaten.

3.3.3. Batı Rumeli Türkçesinin en karakterisik özelliklerinden biri ilk hecede bulunan /ö/ ünlüsünün daralıp /ü/'ye dönüşmesi iken Türkiye Türkçesi ağızlarının büyük çoğunluğunda /ö/ vardır (Gülsevin 2017: 47). Bu yönüyle Molino ve Mascis farklı özellikler gösterir:

Örnekler:

\begin{tabular}{l|l|l} 
Molino & Mascis & Meninski \\
\hline çörek (290) & çürek (117) & çörek (1675) \\
\hline börek (460) & bürek (119, 250) & börek (915) \\
\hline börekci (294) & bürekci (119) & börekçi (915) \\
\hline bölük (107, 230, 427) & bölük (227) bülük (79-80) & bölük (941) \\
\hline böyük (169, 240) böyik (411) & büyük (59, 86) böyük (212) & böyük (952) büyük (949) \\
\hline böyle (56, 109) & büyle (16, 34) & böyle (949) \\
\hline dögmek (69, 374) & dögmek (20) dügmek (20) & dögmek (2112) \\
\hline övke (94) öke (157) ökâ (432) & öke (54, 231) üke (30) & öke (534)
\end{tabular}


3.3.4. 'Yaşayan Batı Rumeli Türkçesinin en karakteristik özelliklerinden biri de kelime başında ve kelime içinde hece başlarında g- > c- / k- > ç- değişmelerinin olmasıdır' (Gülsevin 2017: 53). Mascis'teki bazı kullanımlar bu yönden Batı Rumeli ağızları yanındadır:

\begin{tabular}{l|l|l} 
Molino & Mascis & Meninski \\
\hline göl (226) & çöl (230) & göl (4009) \\
\hline gübre (232) & cibre (81) & gübre (4050)
\end{tabular}

3.3.5. Osmanlı imlasının yazım özelliğinden dolayı çoğu zaman /b/ - /p/, /c/ - /ç/ gibi ünsüzlerin durumunu tespit etmek güçtür. /b/ /p/ seslerini veren kelimeler bakımından her iki metin bazı kelimelerin telaffuzunda farklı özellikler gösterir.

3.3.5.1. Alıntı kelimelerde

\begin{tabular}{|c|c|c|}
\hline Molino & Mascis & Açıklamalar \\
\hline bahadur $(73,471,472)$ & $\begin{array}{l}\text { bahadur }(261) \\
\text { pahadur }(261)\end{array}$ & $\begin{array}{l}\text { Osm. ed. 1680: behādır (behādyr) 'valoroso, brauo, } \\
\text { coraggioso, forte, gagliardo, di gran cuore, guerrire' } \\
\text { (Men. 953). } \\
\text { Etmlj. bahādur 'Held' [kahraman, yiğit] < tü. batur; } \\
\text { bātur 'Held' bayatur (TMEN III §817; ĖSTJa II 82- } \\
\text { 85). }\end{array}$ \\
\hline$\varnothing$ & $\begin{array}{l}\text { pahalıgile (261) } \\
<\quad * \text { pahadurligile } \\
\text { bahadurligile }\end{array}$ & $\begin{array}{l}\text { Krş. osm. 1680: behādirāne (behādirāne) 'da ualoroso, } \\
\text { da brauo, da huomo di cuore, ualorosamente' (Men. } \\
\text { 954); 1789: gayretligile (ghajretlyghile) } \\
\text { 'valorosamente' (Pian-R. 104). }\end{array}$ \\
\hline bazar $(147,252)$ & $\begin{array}{l}\text { pazar }(50) \\
\text { [eş anl. penayır] }\end{array}$ & $\begin{array}{l}\text { Stt. pazar < fars. bāzār 'çarşı veya pazar, alışveriş } \\
\text { edilen yer' (SS 483). }\end{array}$ \\
\hline bide (308) & pide $(51,129)$ & $\begin{array}{l}\text { Osm. pidä, bidä < yun. лíta, píta 'yassı hamur ekmeği' } \\
\text { (Räsänen VEWb. 385; SS 491). }\end{array}$ \\
\hline bogaça (150) & pogaça (51) & $\begin{array}{l}\text { Stt. poğaça < slav. pogač, 'Art Fladen', bulg. pogáča } \\
\text { 'Aschenbrot, Kuchen' (Tietwörter. Slv III 169). }\end{array}$ \\
\hline
\end{tabular}

3.3.5.2. Türkçe kelimelerde

\begin{tabular}{l|l|l} 
Molino & Mascis & Açıklamalar \\
\hline barmak, parmak (116, 182) & $\begin{array}{l}\text { parmak, parımak } \\
(283,38)\end{array}$ & $\begin{array}{l}\text { xiii. yy. barmak; xiv. yy. parmak < ? EsT bar- + mak } \\
\text { 'yürümek' (SS 478). }\end{array}$ \\
\hline buçak (97) & pıçak (30) & $\begin{array}{l}\text { An.-ağl. pıçak 'bıçak' (DS 3439) || Merzifon - Amasya; } \\
\text { Antakya. }\end{array}$ \\
\hline buçak kavgası etmek (11) & plçak kavga etmek (5) & $\begin{array}{l}\text { *Kelimenin türevlerinde Molino brçak kelimesini } \\
\text { daima /b/'li; Mascis /p/'li verir. }\end{array}$ \\
\hline buçak ucı (329) & plçak ucl (143) &
\end{tabular}




\section{Sonuç}

Damak /n/'sinin durumu, ilk hecede /ö/ > /ü/ değişmesi, /h/ > ø gibi Rumeli ağzı (dolayısıyla İstanbul ağzı) özelliklerinin Molino'da bulunmayıp Mascis'te bulunmasının nedeni Ankaralı bir Ermeni olan Molino'nun Türkçeyi Ankara'da öğrenip doğal olarak onun bu ağzı eserinde yansıtmasıdır. Mascis ise bir yabancı olarak İstanbul'da duyduğu telaffuzun en doğrusu olduğunu düşünüp eseri bu yönüyle revize etmiş ve sözlüğünü yeni madde başları ile zenginleştirmiştir.

Revizyon bir intihal değil yeniden 'gözden geçirip düzenleme'dir. Böyle olmasa Farsça kelimelerin anlamları için kullandığımız F. Steingass'ın 1892'de basılan Persian-English Dictionary, 1852'de basılan Francis Johnson'un Dictionary Persian, Arabic, and English'in; Johnson'un çalışması da bu sözlükle aynı isme sahip 1806 ve 1810 'da basılan iki ciltlik John Richardson-Charles Wilkins sözlüklerinin imitasyonu olmalıydı. Fakat herbir baskıda yazarlar eserlerinin revised [= gözden geçirilmiş] olduğunu belirtirler.

Bugünün yaklaşımıyla, Mascis'in en büyük hatası eserinde hiçbir şekilde Molino'dan bahsetmemiş olmasıdır. Mascis'in sözlüğü özgün bir eser olmasa dahi Molino'nun kötü bir taklidi değil, ancak Rumeli ağızlarının bazı karakteristik özelliklerini gösteren ve yeni kelimeler ilavesiyle onun gözden geçirilmiş yeni bir baskısıdır.

\section{Kisaltmalar}

an.-ağl.

ar.

BdP

Borrelli

bulg.

Car-R.

Ciadyrgy

Clauson

Codex

DS

EsT

ÈSTJa.

eş anl.

etmlj.

Fanfani

fars.

Galesini

günl.

ital.

krş.

Letellier
Anadolu ağızları.

Arapça.

Parigi 1665.

Borrelli 1846.

Bulgarca.

Carradori 1650 (bk. Rocchi 2011).

Ciadyrgy 1832.

Clauson 1972.

Codex Cumanicus (bk. Argunşah - Güner 2015).

TDK, Derleme Sözlüğü.

Eski Türkçe.

Ètimologičeskij slovar’ tjurkskih jazykov (bk. Sevortjan 1978).

Eş anlam.

Etimoloji.

Fanfani 1863.

Farsça.

Galesini 1662.

Günlük dil.

İtalyanca.

Karşllı̆̆l.

Letellier 1838 . 
Masc.

Men.

Men. Onom.

Meyer

Mol.

OnEtym.

osm.

osm. ed.

Patriarchi

Pianz-R.

Politi

Ponza

Räsänen VEWb.

Redh.

Rgzz.

slav.

sogd.

SS

StAr.

stt.

\section{TETTL}

Tietwörter.

TMEN

Venuti

yun.
Mascis 1677.

Meninski 1680.

Meninski Onomasticum 1687 (bk. Tulum 2011).

Meyer 1893 (bk. Meyer 1998).

Molino 1641.

Online Etymology Dictionary (www.etymonline.com/).

Osmanlı Türkçesi.

Osmanlı edebi dil.

Patriarchi 1775.

Piaznola 1789 (bk. Rocchi 2009).

Politi 1613 .

Ponza 1843.

Versuch Eines Etymologischen... (bk. Räsänen 1969).

Redhouse 1890.

Ragazzini.

Slavca.

Soğdca.

Sözlerin Soyağacı (bk. Nişanyan 2009).

Studien Über Die Arabischen Lehnwörter... (bk. Stachowski 1975).

Standart Türkiye Türkçesi.

Tarihi ve Etimolojik Türkiye Türkçesi Lugatı (Tietze 2002).

Wörterbuch der griechischen... (bk. Tietze 1999).

Türkische und Mongolische Elemente Im Neupersischen (bk. Doerfer 1967).

Venuti 1576.

Yunanca.

\section{Kaynakça}

Altınsu, A. (1972). Osmanlı Şeyhülislamları. Ankara: Ayyıldız Matbaası.

Argunşah, M., \& Güner, G. (2015). Codex Cumanicus. İstanbul: Kesit.

Borrelli, P. (1846). Dizionario della Lingua Italiana (C. 1). Napoli: Presso Gaetano Nobile EditoreProprietario.

Ciadyrgy, A. (1832). Dizionario Turco, Arabo e Persiano. Milano

Clauson, G. (1972). An Etymological Dictionary of Pre-Thirteenth-Century. Oxford.

Doerfer, G. (1967). Türkische und Mongolische Elemente Im Neupersischen (C. 3). Wisbaden: Franz Steiner Verlag GMBH.

Drimba, V. (1992). La grammaire turque d'Antonio Mascis (1677). Wiener Zeitschrift für die Kunde des Morgenlandes, 82, 109-120.

Fanfani, P. (1863). Vocabolario Dell' Uso Toscano (C. 1-3). Firenze: G. Barbèra.

Galesini, P. (1662). Dittionario, overo Tesoro Della Lingua Volgare e Latina. Roma: Francesco Moneta.

Gülsevin, G. (2017). XVII. Yüzyıl Batı Rumeli Türkçesi. Ankara: TDK. 
Hitzel, F. (Ed.). (1995). Enfants de langue et Drogmans - Dil Oğlanları ve Tercümanlar. İstanbul: YKY.

Karahan, L. (1996). Anadolu Ağızlarının Sinıflandırılması. Ankara: TDK.

Karkartal, O. (2004). Türk - İtalyan Kültür İlişkileri. İstanbul: Eren.

Kurtböke, P. (1994). 17th-century Italian-Turkish Dictionaries. EURALEX [= European Association for Lexicography], 536-541.

Letellier, V. (1838). Vocabulaire Oriental, Français - Italien, Arabe, Turc et Grec. Paris.

Mascis, A. (1677). Vocabolario Toscano e Turchesco. Niccolò Nauesi: Firenze.

Meninski, F. à M. (1680 [Tıpkı basım, 200o]). Thesaurus Linguarum Orientalium Turcicae, Arabicae, Persicae. (S. Stachowski \& M. Ölmez, Ed.) (C. 1-3). Viennæ [İstanbul]: Simurg.

Meyer, G. (1893 [Tipkı basım, 1998]). Türkische Studien, Die griechischen und romanischen Bestandteile im Wortschatze des Osmanisch - Türkischen. (M. Ölmez, Ed.). Wien [Ankara]: In Commission Bei F. Tempsky [Kebikeç].

Molino, G. (1641). Dittionario della lingua Italiana, Turchesca. Roma.

Nişanyan, S. (2009). Sözlerin Soyağacı (6. Baskı). İstanbul: Everest.

Pakalı, M. Z. (1971). Osmanl Tarih Deyimleri ve Terimleri Sözlüğü (C. 1). İstanbul: MEB.

Parigi, B. da. (1665). Söz Kitâbr - Vocabolario Italiano - Turchesco. (P. d’Abbauilla, Çev.) (C. 1-3). Roma: Nella Stamparia della Sac. Congreg. di Propag. Fide.

Patriarchi, G. (1775). Vocabolario Veneziano e Padovano Co'Termini, e Modi Corrispondenti. Padova: Nella Stamperia Conzatti.

Politi, A. (1613). Dittionario Toscano. Roma.

Ponza, M. (1843). Vocabolario Piemontese-Ital. e Italiano-Piem. Torino: Tipografia di Gio. Battista Paravia e Comp.

Ragazzini, G. (2015). Dizionario Inglese - Italiano, Italiano Inglese. Bologna: Zanichelli.

Räsänen, M. (1969). Versuch Eines Etymologischen Wörterbuchs Der Türksprachen. Helsinki: Suomalais - Ugrilainen Seura.

Redhouse, S. J. W. (1890 [Tipkı basım, 2001]). A Turkish and English Lexicon (2. Edition). Constantinople [İstanbul]: A. H. Boyajian [Çağrı Yayınları].

Rocchi, L. (2009). l lessico turco nell'opera di Bernardi Pianzola Materiali per la conoscenza del turco parlato di fine Settecento. Trieste: Edizioni Università di Trieste (EUT).

Rocchi, L. (2011). Turco - Ottomano di Arcangelo Carrdori (1650). Trieste: Edizioni Università di Trieste (EUT).

Rocchi, L. (2011). Turkish historical lexicography. Lexicographica, (XXVII), 195-220.

Sevortjan, E. V. (1978). Ėtimologičeskij slovar'tjurkskih jazykov (C. 2). Moskva: Nauka.

Siemieniec-Gołaś, E. (2005). Turkish Lexical Content in Dittionario della lingua Italiana, Turchesca by Giovanni Molino (1641). Kraków: Księgarnia Akademicka.

Stachowski, S. (1975). Studien Über Die Arabischen Lehnwörter Im Osmanisch-Türkischen - Teil I (AI). Wrocław/Warszawa/Kraków/Gdańsk: Wydawnictwo Polskiej Akademii Nauk.

Święcicka, E. (2000). Interpreter Yovhannēs Ankiwrac'i also called Giovanni Molino. Folio Orientalia, $X X X V I, 329-342$.

TDK. (1983-1993). Derleme Sözlüğ̈̈ (C. 1-12). Ankara: TDK.

Tietze, A. (1999). Wörterbuch der griechischen, slavischen, arabischen und persischen Lehnwörter im Anatolischen Türkisch - Anadolu Türkçesindeki Yunanca, İslavca, Arapça ve Farsça Ödünçlemeler Sözlüğü. İstanbul: Simurg. 
Tietze, A. (2002). Tarihi ve Etimolojik Türkiye Türkçesi Lugatı - Sprachgeschichtliches und Etymologisches Wörterbuch des Türkei-Türkischen $I$ (A-E). İstanbul/Wien: Simurg/Österreichische Akademie der Wissenschaften.

Tulum, M. (2011). 17. Yüzyıl Türkçesi ve Söz Varlı̆̆ı. Ankara: TDK.

Venuti, F. (1576). Dittionario Volgare et Latino. Roma: Nelle Case del Popolo Romano.

\section{Elektronik Kaynakça}

Harita: https://en.wikipedia.org/wiki/Rodi\%2oGarganico

Online Etymology Dictionary (www.etymonline.com/).

The Medici Archive Project (www.medici.org/) 